\title{
Symposium
}

\section{Conceptualizing political participation}

\author{
Marc Hooghe, Bengü Hosch-Dayican and Jan W. van Deth
}

Acta Politica (2014) 49, 337. doi:10.1057/ap.2014.7; published online 16 May 2014

Citizen participation in politics has always been a defining characteristic of democracy. Empirical research into political participation therefore practically always results in an assessment of the state of democracy as well. But what counts, and what does not count as political participation? At least since the 1960s, scholars have provided different conceptualizations of political participation. The concept has been broadened not only to reflect changes in theory but also in response to social and technological developments. As a result, a wide and ever increasing variety of definitions and conceptualizations are currently employed. Jan van Deth proposes an encompassing conceptual map in order to capture past, present and future forms of political participation. Marc Hooghe and Bengü Hosch-Dayican criticize his proposal. Hooghe argues that the politics at which political participation is aimed is a moving target itself, whereas Hosch-Dayican wants more attention for motivational criteria at a time when online participation is often not clearly instrumental in nature. In a rejoinder, van Deth replies to their criticisms. 


\title{
Symposium
}

\section{Defining political participation: How to pinpoint an elusive target?}

\author{
Marc Hooghe \\ University of Leuven \\ E-mail: Marc.Hooghe@ soc.kuleuven.be.
}

Acta Politica (2014) 49, 338-341. doi:10.1057/ap.2014.7; published online 16 May 2014

The contemporary literature on political participation covers a wide array of actions that would not have been included in the handbooks on the topic just a few decades ago. By itself this expansion should not come as a surprise, as citizens indeed are now active in more, and more different ways than previous generations used to be. My grandfather never used a 'Like' button on his Facebook profile to express his political preferences, and my grandmother certainly never would have joined the Femen protests that are so successful in attracting media coverage. The character of political participation has changed, and as political scientists we have no other option than to follow this social trend. Holding on to traditional definitions is not a useful strategy to help us to understand societies that have changed so rapidly.

These changes have indeed led to an inflation in the number of acts being included in the definition, and an attempt to arrive at a more appropriate definition is certainly useful. While the introduction of the concept of lifestyle politics has had a number of obvious advantages, expanding the definition to cover almost every lifestyle decision automatically renders the definition meaningless. As the function of politics is to structure the way in which societies function, every human act can become politically relevant at some time. If a sufficient number of tourists develop a preference for nude beaches, local government officials eventually will have to respond to this social demand, resulting in a political decision. It would be rather absurd, however, to label this kind of leisure activity automatically as a political act itself, with as only motivation that it will, or might have some political consequence eventually. So bringing in 'politically relevant behaviour' really opens up a Box of Pandora, and all forms of human behaviour will have to be labelled as political. I do not think this is a useful strategy.

Basically, however, I doubt whether the current text solves all the problems if we want to arrive at a more precise definition. Although van Deth is a strong believer in 
the merits of an operational definition, this is not the best way to bring more clarity in this debate. Operational concerns are indeed important, but they are what they are. Operational decisions cannot do anything else than to operationalize a theoretical concept. Operational criteria do not help us to decide what we should study and how; they merely help us to delineate our concepts. So the logical order would have been first to develop a meaningful theoretical concept of political participation, and subsequently to try to operationalize this.

Despite all the obvious merits of the text, I would still argue that Van Deth does not pay sufficient attention to developing a theoretical foundation for this conceptual framework. A number of elements are indeed quite 'unproblematic', as they are included already in the classical definition by Verba et al (1995, p. 38), as they define political participation as an 'activity that has the intent or effect of influencing government action - either directly by affecting the making or implementation of public policy or indirectly by influencing the selection of people who make those policies'. It is a correct statement that most of these criteria do not lead to strong debates on the topic. One can wonder, however, whether acts of political participation necessarily have to be voluntarily, as it is stated. The obvious example would be compulsory voting. In that case, the state orders citizens to cast their vote during elections, but by itself that does not mean that this act of voting becomes meaningless or would become less influential than voting without any form of obligation. As Gertrude Stein would have it: a vote is a vote, and whether the vote is compulsory or voluntarily does not change anything with regard to its impact.

It is also quite dubious to include the intention of the individual participants themselves as part of the definition. There are three main reasons not to take this step. First of all, it is very difficult to determine what exactly is the intention for participation among people who are active. This can be asked, of course, for example, by means of a survey among participants. But even then it would be very difficult to do this in an unequivocal manner as participants usually have a number of motivations to participate or not. Furthermore, this only shifts the question. Quite a few participation acts are performed mostly with an expressive motivation, that is, that participants enjoy the act itself, without necessarily having an instrumental motivation. This does not mean, however, that this participation becomes meaningless: expressive acts are just as meaningful as purely instrumental acts of participation. Second, even when we could measure the intentions of participants in a valid manner, by no means should we assume that participants themselves always know what their motivation is. Participants can have multiple motivations, these can interact, and participants can also convince themselves on a good story about their own motivations. I remember that when I was a student, we used to have all kinds of demonstrations against the policy on university education. In retrospect, I am not even sure anymore what my own motivation was at the time. Just the excitement of these demonstrations and the fact that my girlfriend was clearly impressed were also strong motivations, I would say with hindsight. The third, and maybe most 
fundamental argument, however, is that intention simply is not relevant. Maybe I did only participate in these student demonstrations to impress my girlfriend, but the minister of education did not know this, and in the end we indeed prevailed and the student movement was successful in blocking the intended reforms. I would argue, therefore, that it does not really matter what the motivation is of the participants, even if when we could determine what these intentions are.

An important shortcoming in the current text, therefore, is that it is not fully clear what the goal of the text is. On the one hand, the aim is to develop a coherent definition, and here the text does indeed offer an important contribution to the literature. Despite the fact that it is often claimed that 'politics' is no longer an exciting topic for younger age groups, in practice it can be observed that actors still are very strongly attracted to the label. If one suggests that a specific act does not qualify as political participation, reactions are usually negative. There is nothing wrong with being a vegetarian, and whether this act is considered as an act of political participation or not, does not imply a judgement on the merits of this kind of behaviour. Nevertheless, people often do feel insulted if their behaviour is not seen as 'political participation'. Apparently, vegetarians themselves feel their preferences are taken more seriously if they are labelled as a form of political participation than if they are not, and this explains a kind of pressure to continuously expand the definition of the concept. So a merit of this text is indeed the effort to limit the boundaries of the concept, and if we do not do this, the concept becomes altogether meaningless.

However, subsequently, this strong coherence is blurred again by distinguishing different forms of participation, even arriving at the very ambiguous category of nonpolitical activities that are politically motivated. This is indeed a very blurry category, and it should not be part of a rigorous exercise to define political participation. Selfevidently there will also be a grey zone of acts that more or less fit the definition but do not offer a perfect fit. Even without being an essentialist, it is clear, however, that one does not need a specific definition for this grey zone. Almost by definition, a definition covers the 'essence' of a concept, or the concept in its purest form. Later on, in operational discussions, one can still judge whether a specific entity complies with the definition of the concept and, if so, to what extent. But it is not a good strategy to make a definition in itself for these 'grey zone' cases.

These, admittedly, rather critical remarks about the current proposal should not lead to the impression that there are no real problems with the standard definitions as they are being used in most of the literature. Although I personally would still begin with the approach developed by Verba et al (1995), the main problem is that they could still depart from the criterion that there should be a relation with 'government policy'. Indeed, if political decision making is situated mostly or even exclusively within the political institutions, the definition is rather straightforward. Any act that can or will have an effect on local or national political institutions in that case counts as 'political participation', and there is not much debate about that option. The main 
problem, however, is that political decision making by itself has become something of a moving target. If activists want to have an effect on, for example, environmental policy, it is clear that they can no longer suffice with targeting their own national government. The process of political decision making has become much more diffuse, with tendencies towards horizontal governance structures and networks, globalization and multi-level government. All these tendencies occur simultaneously and they also interact (Huyse, 1994; Della Porta, 2013). Citizens who want to have an impact on political decision making have no other option than to broaden their participation repertoire. They will be forced not just to target their national government, but also various international organizations and agencies that have an impact on environmental policy. Given the fact that there is a trend towards selfregulation among commercial companies, it becomes equally important to target these companies or their business associations in a more direct manner. One could say that life has become more difficult for political activists: the proliferation of political decision making in practice means that they will have to be active in numerous policy arenas simultaneously.

What does this imply for political participation scholars? To some extent, one could compare political science scholars with the Sámi people, living in the northern part of Scandinavia. As they are completely dependent on the reindeer population for their survival, the Sámi have no other option than to follow the migrations of the reindeer herds. Political behaviour scholars, too, are completely dependent on the migratory behaviour of our topic. If political activism migrates to transnational organizations, or to Facebook, or to other arenas, we do not have any other option than to follow them. If our definitions do not follow the structural trends occurring in reality, in the end we will simply be left out, using outdated categories and concepts.

Political decision making has become diffuse, and can be seen as the result of a complex interplay between actors situated at various geographical levels. As a result, political participation, too, has moved. Self-evidently, definitions and concepts have to be as clear and concise as possible. However, if the pellucidity of the topic that we want to investigate itself has diminished, we do not have any other option than to follow this trend. Inevitably, this means that the study of political participation, let alone the study of its effects or motivations, will become more complicated than ever before.

\section{References}

Della Porta, D. (2013) Can Democracy be Saved? Participation, Deliberation and Social Movements. Cambridge: Polity.

Huyse, L. (1994) De politiek voorbij. Een blik op de jaren negentig. Leuven, Belgium: Kritak.

Verba, S., Schlozman, K.L. and Brady, H. (1995) Voice and Equality. Cambridge: Harvard University Press. 


\title{
Symposium
}

\section{Online political activities as emerging forms of political participation: How do they fit in the conceptual map?}

\author{
Bengü Hosch-Dayican \\ University of Twente \\ E-mail: b.dayican@utwente.nl.
}

Acta Politica (2014) 49, 342-346. doi:10.1057/ap.2014.7; published online 16 May 2014

\begin{abstract}
'A Conceptual Map of Political Participation' by Jan van Deth revisits what we know about political participation, and proposes one of the most comprehensive conceptualizations of participation ever. It is characterized by two important attempts: the expansion of the definition of political participation and the differentiation between analytical types of participation, both along a series of criteria derived from participatory theory and practice. This article is an important contribution to the field of political participation to the extent that it allows for a systematical identification of various phenomena as a specimen of political participation and thus has the potential to keep up with the rapidly evolving character of the concept. At the same time, it is a very ambitious endeavour to have drafted a dynamic conceptual framework that claims to apply to all existing forms of participation as well as to those forms that are yet to emerge. However tempting it may sound, such a claim always calls for a careful and critical approach.

In this review, I discuss the plausibility of this framework by focusing upon online political action repertoires taking place on the Internet and social network sites (SNS). Activities such as posting messages with political contents on personal blogs and SNS profiles, joining discussions on Internet forums or 'liking' pages of politicians, parties or movements have become widespread in recent years. Considering the increasing amount of attention paid to such activities in newer literature, this novel domain is particularly relevant to evaluate the dynamic conceptual model offered by van Deth. Currently, there are two actual debates among scholars related to digital modes of participation. The first one is related to the definition of these new forms as political participation. The general argument offered by the critics is that most of the online activities do not go beyond communicative acts; or they are simply
\end{abstract}


dismissed as 'clicktivism' or 'slacktivism' (Christensen, 2012). The second discussion concerns where to place these activities in the 'hierarchy' of online and offline political acts, that is, whether or not to treat them as separate constructs. To what extent can the theoretical approach suggested in this article offer a remedy for these dilemmas? As I will show in the following, this might be far less simple than it seems, or is claimed by van Deth.

Let us begin with applying the operational definition to the question whether online activities are political participation. Classical definitions imply that political participation is intended to influence the decision-making process directly or indirectly, and thus stress the instrumentality of the act. From this perspective, any form of political engagement that is targeted at another goal than influencing government decisions or attaining some policy consequences would not qualify as participation. As a matter of fact, most of these definitions that have been provided before the digital era are still the most cited ones even within the contemporary research on political participation. However, in the light of the recent social and technological changes, newer accounts advocate the position that new politics is increasingly personalized and takes place to a great extent outside of the domain of institutionalized policy making. Consequently, political participation today is more generally perceived as taking part in the expanded domain of politics rather than solely contributing to the policy-making processes. Activities in this new political sphere are accordingly prone to be marked by a less instrumental, but a more symbolic or expressive character. This makes an updated definition of political participation indeed necessary to cover new activity forms. Van Deth's operational definition of political participation is an adequate solution to this need. Particularly the new component, political motivation, which is supposed to be existent if the activity is used to 'express political aims and intentions of the participants', opens the possibility to include new forms of political activities resulting from the swiftly developing digital information and communication technologies. In this way, online activities such as posting comments, opinions, information or audiovisual material on websites, blogs or SNS can be accommodated in the concept of political participation as long as they are directed at the expression of a political motive.

Hence, can we conclude that the expanded definition offers a satisfactory answer to the debate on the participatory character of online political activities? Not so hastily. The trouble is that the motivational criterion, which is the utmost boundary of activities that can be called political, is highly blurred and does not satisfactorily draw a clear line between participation and non-participation. The article features no concrete definition of what is meant by political aims and intentions, as this can allegedly only be answered by the person involved (see note 14). Non-political aims and intentions are exemplified in the text as 'attending a demonstration to find a partner' or 'vote for a particular party to avoid conflict at home'. Thus non-political participation consists of activities aimed at satisfying a personal benefit that is not directly related to the act itself. Whether such intrinsic rewards motivate the 
behaviour is, however, very difficult to assess. Obviously, one cannot ask each specific participant if they perform their actions to reach a personal or a political goal; even if that would be possible, the chance is high that the answers will be biased by the social desirability effect. Providing a solid definition of political motivations with more clearly defined criteria is therefore very important for those activities that basically live from the motivational criterion, as in the case of political activities via online platforms. For some of these acts it is relatively easy to determine whether a political motivation is existent, whereas for others it might not be that simple. For instance, posting a Facebook message to express discontent with the government's health-care policies is quite likely to have a political aim. But what about more passive acts such as 'liking' a political message sent by a Facebook contact? It can be motivated by an urge to express that the person shares his contact's political view, or alternatively, just to be nice to a friend by supporting his cause. As this is not easy to determine by simple observation, defining criteria for political motivations is absolutely necessary.

Such criteria will be pivotal for preventing that all kinds of online behaviors will be added to the repertoire of political participation without further ado, and grant the concept of participation internal consistency. Furthermore, they would draw a solid conceptual outline that helps to distinguish political participation systematically from other, related concepts. The concept of political communication is a relevant example to demonstrate why this is important. A review of the extant literature shows that already a large number of activities are included in different measurements of online political participation, whereas some scholars have counted political information seeking on the Internet or on SNS also among the indicators of new online modes of engagement (for example, Gil de Zúñiga et al, 2010; Hirzalla and Van Zoonen, 2011; Linaa Jensen, 2013). As is known, offline versions of these acts are traditionally perceived as political communication and thus not considered within the repertoire of political participation. However, in the case of online activities, it is hard to draw a line between political participation and communication as these activities are by definition communicative (Hoffman, 2012). Without a more elaborate definition of political motivations, the new conceptual map proposed here can hardly deal with this challenge. Attention to political news, sharing news contents or commenting on these contents can be identified as non-political participation on the map as they lack the motivation of expressing a political intention at a first glance. However, on the online SNS, such activities become available to a larger public owing to the high connectivity of these platforms, and therefore they are more likely to reach, influence and mobilize citizens in these networks. In addition, they allow for the expression of the sender's political beliefs, allegiances and intentions. Because of this, it is often argued that political news attention and sharing take on a more instrumental and active quality once they are performed via online channels, and thus they get an 'upgrade' to constitute authentic participatory acts (Gibson and Cantijoch, 2013, p. 704). 
This brings us to the discussion on the divide between online and offline political behaviour in the digital age. While some scholars treat online political behaviour as an extension of offline participatory practices, others argue that online and offline political acts are separate constructs that take place in separate spheres. Recent studies show that online participation indeed constitutes a separate dimension, and that even online activities might have multiple dimensions (for example, Gibson and Cantijoch, 2013; Valenzuela, 2013). If this is the case, can the fourfold typology of political participation proposed by van Deth adequately address this online-offline divide? And to what extent can novel online political activities - such as those on SNS - be accommodated unequivocally within any type of participation suggested in the conceptual map? These are important questions as putting online and offline versions of the same act in one category is likely to cause methodological drawbacks once a measurement instrument for these four types of participation is developed. The challenge is that even though some online activities look like their offline counterparts, they might occupy separate spheres of activity. This can best be illustrated by an example. Contacting politicians offline, or sending an electronic message to their personal email addresses, unequivocally fulfil the criteria for the minimalist definition; it takes place within the locus of government and therefore can be located within Political Participation-I on van Deth's conceptual map. Yet, does the same apply to sending a tweet addressed at the prime minister? It is targeted at a government official and thus within the locus of institutionalized politics; however, it is at the same time available to all followers of the sender and of the prime minister. In this way, the demand formulated in the tweet will be communicated to a larger audience and become an online opinion expression, which fits in Political Participation-IV. From this example, it follows that activities taken on the Internet and SNS can be much more complex by nature than similar off line acts, which makes a watertight classification of new online activities, along the criteria suggested by van Deth, extremely difficult. More fine-grained classifications are also necessary for sound measurements of online political participation and its sub-categories.

In the light of the discussion presented above, it can be concluded that the conceptual framework of political participation as proposed in the article does not live up to all its claims when applied to the recently emerged online activities. From a theoretical perspective, I agree with most points addressed in the text. Political participation is a dynamic concept, and its classical instrumental definitions are just too restrictive in the era of digital communication technologies. Expanding these definitions by adding a motivational criterion allows for the identification of online activities - which are primarily directed at expressing individual opinions rather than influencing the institutionalized policy-making processes - as political participation. These strengths notwithstanding, this short analysis has shown that some aspects of the framework need a more thorough reflection. Most importantly, the motivational criteria for defining participation need to be more concrete. This is a crucial step to distinguish political participation from other phenomena, and to prevent its 
conceptualization from becoming a theory of everything. Studying the political contents of online messages, comments or other activities - particularly by concentrating on SNS - can provide fruitful insights while establishing the criteria for political motivations.

\section{References}

Christensen, H.S. (2012) Simply slacktivism? Internet participation in Finland. JeDEM - Journal of eDemocracy and Open Government 4(1): 1-23.

Gibson, R.K. and Cantijoch, M. (2013) Conceptualizing and measuring participation in the age of the internet: Is online political engagement really different to offline? The Journal of Politics 75(3): 701716.

Gil de Zúñiga, H., Veenstra, A., Vraga, E. and Shah, D. (2010) Digital democracy: Reimagining pathways to political participation. Journal of Information Technology \& Politics 7(1): 36-51.

Hirzalla, F. and Van Zoonen, L. (2011) Beyond the online/offline divide: How youth's online and offline civic activities converge. Social Science Computer Review 29(4): 481-498.

Hoffman, L.H. (2012) Participation or communication? An explication of political activity in the internet age. Journal of Information Technology \& Politics 9(3): 217-233.

Linaa Jensen, J. (2013) Political participation online: The replacement and the mobilisation hypotheses revisited. Scandinavian Political Studies 36(4): 347-364.

Valenzuela, S. (2013) Unpacking the use of social media for protest behavior: The roles of information, opinion expression, and activism. American Behavioral Scientist 57(7): 920-942. 


\title{
Symposium
}

\section{Rejoinder}

\author{
Jan W. van Deth \\ University of Mannheim \\ E-mail: jvdeth@uni-mannheim.de.
}

Acta Politica (2014) 49, 347-348. doi:10.1057/ap.2014.7; published online 16 May 2014

To stimulate discussion was the foremost aim of my article, and I am very grateful to Marc Hooghe and Bengü Hosch-Dayican for the way they accepted this challenge. In this brief rejoinder I focus on four important issues: (i) why develop a conceptual map, (ii) how to avoid intentions, (iii) where do social media fit in, and (iv) what do we learn from the Sámis?

As Hooghe reminds us, defining concepts should start from theory. In the introduction I showed that this does not work for political participation because various conceptualizations - not theories - result in very different conclusions. More importantly, the list of phenomena called political participation is expanded almost daily and no set can convincingly claim to operationalize the concept. It is not the concept, but its theoretical and empirical use that triggers ambivalent and contradictory conclusions. My pragmatic proposal is to specify necessary and sufficient conditions for political participation; that is, to specify properties for a minimal definition. A systematic overview is obtained by mapping these properties as a set of decision rules for an operational definition. Hooghe uses a different understanding of operational definitions than the one I borrowed from Hempel and sticks to the conventional way to define and operationalize concepts in empirical (behaviourist) research. As I have tried to make clear, this approach does not help us much with the problems we face studying political participation.

Amazingly, the two discussants reach diametrically opposite conclusions on the question how to deal with intentions. For Hosch-Dayican, intentions provide 'the utmost boundary of activities that can be called political' and she urges for 'motivational criteria', whereas Hooghe strongly contests such ideas because 'intention simply is not relevant'. The problems, I think, require a more nuanced approach. Whereas some activities are clearly political, other can be political or not. For non-political activities, only the expression of political aims is conclusive - and highly problematic. Furthermore, consistency requires that other modes of participation have to fulfil the same criterion; that is, participation would only be participation if the participant explicitly endorses political goals. In this way, we sink even deeper 
into the swamp. Many new modes of participation rely on expressions and cannot be simply neglected. Hooghe's statement of irrelevance is correct for his student protest (a rather simple example of Type-II Participation), but if he really would neglect intentions he would not recognize political participation even if he was in the middle of a product buycott or a poetry slam. The map integrates intentions only at the very end, and I do not see how (and why) they can be neglected entirely (the sharp differences of opinion between the discussants seem to support this view). In this way, depicting main modes of participation is not encumbered with intentions, while some modes are systematically portrayed as what they are: non-political activities used for political purposes.

New modes of participation offered by the Internet are not only unimaginable for Hooghe's grandparents. The gospel of new social media is omnipresent (including discussions about 'connective action' and 'slacktivism') and the confusion about communication, mobilisation, and participation seems ineradicable. Applying the proposed decision rules to specific Internet activities is, as Hosch-Dayican confirms with several examples, not only 'extremely difficult', but also, I think, very rewarding. As she shows, contacting a politician on the net is a specimen of Type-I participation. Sending a Tweet changes this conclusion - just as visiting the office hours of an alderman is not the same as putting up posters about some concern in your pub. The crucial distinction is not between 'online' and 'offline' modes of participation (otherwise a separate decision rule should address that feature), but between the properties of distinct modes of participation. The rules do not make such depictions necessarily easier, but offer opportunities for systematic arguments and decisions.

Finally, Hooghe's Sámi metaphor is very helpful. Last summer I visited the Boazo Sámi Siida at the Alta River. Most reindeer were grazing on impassable terrain miles away from the camp. No Sámi I met would mistake a reindeer for a moose or a tundra reindeer for a woodland specimen. They characterized reindeer carefully according to age, sex, colour, antlers, appearance, nature and several other features relevant for husbandry. Obviously, the Siida would follow their herds wherever the animals might go, but they would never call an unknown creature on their grounds a 'reindeer' nor would they follow the migration of other animals than their own reindeer. In fact, the survival of the Sámis impressively shows how important it is to recognize a reindeer if you see one. The conceptual map of political participation is an attempt to do exactly the same in a world that gradually has become as inaccessible as the Sámi territory. 